\title{
Status of New HIV Infections among Infants Born of HIV Positive Mothers on Prevention of Mother to Child Transmission at Kisii Teaching and Referral Hospital, Kenya
}

\author{
Mercy Nyanchama Abere ${ }^{1 *}$, Grace Moraa Omoni², Theresa Mary Odero ${ }^{3}$, Peter Ondieki Atai ${ }^{4}$ \\ ${ }^{1}$ Community Health Nursing, University of Nairobi, Eldoret, Kenya \\ ${ }^{2}$ School of Nursing Sciences, University of Nairobi, Nairobi, Kenya \\ ${ }^{3}$ Department of Community Health Nursing, School of Nursing Sciences, University of Nairobi, Nairobi, Kenya \\ ${ }^{4}$ Memorial Hospital, Ministry of Defence Force, Nairobi, Kenya \\ Email: *mercyabere@gmail.com
}

How to cite this paper: Abere, M.N., Omoni, G.M., Odero, T.M. and Atai, P.O. (2018) Status of New HIV Infections among Infants Born of HIV Positive Mothers on Prevention of Mother to Child Transmission at Kisii Teaching and Referral Hospital, Kenya. Open Journal of Pediatrics, 8, 347-365.

https://doi.org/10.4236/ojped.2018.84035

Received: November 15, 2018

Accepted: December 22, 2018

Published: December 25, 2018

Copyright $\odot 2018$ by authors and Scientific Research Publishing Inc. This work is licensed under the Creative Commons Attribution International License (CC BY 4.0).

http://creativecommons.org/licenses/by/4.0/ (c) (i) Open Access

\begin{abstract}
Introduction: The goal of Prevention of Mother to child Transmission (PMTCT) is to minimize new HIV infection with PMTCT interventions which can reduce to as low as $2 \%$. Gusii region is number 5 among counties that contribute to $65 \%$ of new HIV (Human Immunodeficiency Virus) in infections in Kenya. The study was to determine the prevalence of new HIV infections among infants (3 - 18 months) born of HIV positive mothers on PMTCT follow up at Kisii Teaching and Referral Hospital (KTRH). Method: This was a descriptive cross sectional study involving 96 infants born of HIV positive mothers on PMTCT programme at Kisii Teaching and Referral Hospital (KTRH) was conducted. The infants were between 3 to 18 months of age. The infants were investigated for their HIV status and factors associated with prevalence. The data collection was done during postnatal checkups, antiretroviral treatment follow up and immunization schedule. Data was analyzed using Statistical Package for Social Sciences (SPSS) version 20. Results: $13.5 \%$ (95\% C.I $=10.1 \%$ to $16.9 \%)$ were found to be positive despite their mothers being on PMTCT program. There was no significant difference between gender and status of the infant $\left(\chi^{2}=0.758, \mathrm{df}=1, \mathrm{p}\right.$-value $\left.=0.0384\right)$. Conclusion: The study confirms that there are still new HIV infections despite being followed up in the PMTCT program. The new HIV infections were associated with mixed feeding. Recommendation: Counseling on Infant feeding, use of ant-retroviral treatment and support from partners should be strengthen in the PMTCT program to ensure reduction of new HIV infections.
\end{abstract}




\section{Keywords}

HIV Exposed Infants, HIV Status, HIV Positive Mothers, PMTCT Follow Up, New HIV Infections

\section{Introduction}

It is estimated that 35.3 million people worldwide with more than two-thirds living in Sub Saharan Africa live with HIV and AIDS (Acquired Immunodeficiency Disease Syndrome) [1]. Despite the scale up on the Prevention of Mother to Child Transmission (PMTCT) programs, in 2012, over 210,000 new HIV infections still occurred among infants in Sub Saharan Africa [2]. Globally, Acquired Immunodeficiency Syndrome (AIDS) accounts for three percent of deaths in children below five years of age whereas six percent in Sub Saharan Africa, where it is the major killer of young children [3].

Kenya has adopted the World Health organization on the four pronged approach for the prevention of mother to child transmission of HIV. This approach includes: primary prevention of women of childbearing age, preventing unintended pregnancies among women living with HIV, preventing HIV transmission from women living with HIV to their infants and providing appropriate treatment, care and support to mothers living with HIV and their children and families [1] [4] [5] [6]. Thus, to eliminate the new HIV infections to infants, the four pillars will be employed; however, the third component should be strengthened on use of antiretroviral prophylaxis to reduce the transmission rate from mother to child.

The global report on HIV and AIDS epidemic 2013, indicates that most of the new HIV infections among infants were reported mostly from Sub Saharan region. The countries in the region were categorized as priority countries in the virtual elimination of new HIV infections by 2015 [5]. The report [5] indicates that 210,000 newly infected children were reported in 2012 which showed $37 \%$ drop from 2009 and indicates that with effective intervention the rate can still be reduced. However, there are still infections which are reported through breast feeding period. In Kenya, the prevalence rate is 13,000 which signifies a reduction of $44 \%$ from the year 2009. Among women living with HIV only $58 \%$ received anti-retroviral prophylaxis leading to a prevalence of Mother to Child Transmission (MTCT) rated at $15 \%$ [5].

Adoption of PMTCT program in Kenya started in the year 2000. This worked well through piloting in several government clinics which led to substantial scale up with more health facilities providing the services according to WHO 2006 PMTCT guidelines [7] [8]. HIV prevalence is rated at 5.6\% among age grouped between 15 to 64 years. On gender issues, it was higher in female at $6.9 \%$ than male at $4.4 \%$ infected with HIV. This showed that the HIV infection is mostly in women of reproductive age and therefore, the likelihood of passing the infection 
to the infant is high. According to Kenya Aids Indicator Survey (KAIS), 2012, HIV prevalence was higherin urban at $6.5 \%$ and thenrural area at $5.1 \%$ in terms of residence, and geographical. Regionally, it was highest in Nyanza region was highest at $15.1 \%$ in which Kisii county is part of it [1].

The studies have showed that the risk of transmission of mother to child transmission rate ranges between $15 \%$ - 45\%, but with effective intervention this can be reduced to as low as 5\% [5] [9]. Trials have demonstrated that provision of ARV to breastfeeding mothers or their infants can reduce total mother to child transmission to $1 \%-5 \%$ at six months [10]. Arising from this background, there is needed to eliminate new HIV infections among infants.

This basis of this study was to scale up PMTCT program to eliminate new HIV infections among HIV exposed infants. The study was to add knowledge to existing findings on transmission of new HIV infections towards universal millennium development goals on goal 4,5 , and 6 . The study was utilized by the facility in tackling the gap that was identified. Consequently, this study promoted evidence based practice in helping mothers on PMTCT program in virtual elimination of new HIV infections and a guide in planning health programs. The study determined the status of new HIV infections among HIV exposed infants and factors associated with it at Kisii Teaching and Referral hospital, a referral government hospital covering South Nyanza, South rift and entire Gusii region.

\section{Methods}

This was a descriptive cross sectional study to determine the status of new HIV infections among HIV exposed infants on PMTCT follow up and its associated factors. The transmission of mother to child transmission occurs in utero, during labour and delivery and through breastfeeding. To eliminate mother to child transmission, a comprehensive a four pronged approach is established. First is reduction of HIV incidence through VCT among women. Secondly is to reduce unmet need of family planning to zero among all women. Thirdly is reaching over 90\% HIV positive mothers with ARVs (anti-retroviral) drugs to reduce vertical transmission rate. Fourth is to reduce HIV related maternal deaths and reduction in HIV attributable deaths among infants and children below 5 years.

In Kenya, the PMTCT guidelines recommends that HIV exposed children should be followed up in a health facility within two weeks after delivery or first contact through 2 years or 24 months old and this is followed by the monthly visits which are linked to immunization and growth monitoring return dates schedule. The early infant diagnosis of the HIV exposed infants is done from 2 weeks after delivery. This is performed by a routine dry blood spot (DBS) for DNA PCR (Deoxyribonucleic acid Polymerase Chain Reaction) for all infants who are exposed or first contact, to all sick infants in outpatient setting and in the paediatrics wards. If the infant is exposed at 6 weeks, an antibody testing is repeated at 9 months because children lose their maternal antibodies at this age. Another repeat is later done at 18 months. If the baby breast feeds and the anti- 
body testing turns negative at nine months a repeat antibody test is done at 2 months after stopping to breast feed. If the antibody turns positive, it is likely to be diagnostic but may still carry maternal antibodies passively and this will be repeated at 18 months for confirmation with a DNA PCR. HIV exposed infants are enrolled to the PMTCT program and initiated on co-trimoxazole prophylaxis from 6 weeks of age. For infants who test HIV positive co-trimoxazole prophylaxis is given for life. On the other hand, if the infant test negative co-trimoxazole is stopped if the infant is not breastfeeding for 2 months or more. However, if still breast feeds, status is confirmed and co-trimoxazole is continued until 2 months after complete cessation of breastfeeding. The rationale is to protect against common bacterial infections like, Malaria, toxoplasmosis and Pneumocystis Jirovecii which is a significant cause of morbidity and mortality among children below 5 years. If the HIV positive mother does not breast feed in the first 2 months and the HIV test is negative the co-trimoxazole is stopped and a confirmation is done at 18 months. If it turns positive at 6 weeks, breast feeding is done to a minimum of one year, triple anti-retroviral therapy and co-trimozaxole is started regardless of the $\mathrm{WHO}$ staging and $\mathrm{CD}_{4}$ count.

\subsection{Study Area Setting}

The study was conducted at Kisii Teaching and Referral Hospital PMTCT clinic situated at MCH (Maternal and Child Health) clinic from 17th July to 6th August 2014. The hospital is located at Kitutu Chache South, in Kisii County. It has more than 430 beds capacity which serves as a regional referral health facility for South Nyanza, South Rift and the entire Gusii region. The $\mathrm{MCH}$ clinic is divided into different units within the same hospital namely; the Child welfare clinic, postnatal follow up clinic, emergency room and admission room for sick children under 5, Provider Initiated Testing and Counseling (PITC) and Voluntary Counseling and Testing (VCT) rooms, ANC clinic, nutrition room, and three consultation rooms. In the $\mathrm{MCH}$ clinic, approximately 200 postnatal HIV positive mothers with their infants are seen and followed up on a monthly basis. HIV positive mothers' are offered various services that promote safe delivery, ensures safe postnatal care and support for both the infant and the mother. This service includes: voluntary HIV counseling and testing to pregnant women and antiretroviral therapy regimen provided to prevent mother to child transmission. Other services include early infant diagnosis for infants below 18 months old, family planning services, and Provider Initiated Testing and Counseling for HIV and AIDS. The PMTCT mothers are initiated through voluntary HIV testing during pregnancy accompanied with their partners during their initial visit. During labour and delivery a repeat of HIV testing is done to all mothers delivering in the unit. A follow up HIV testing is done postnatally at six weeks after delivery. Dried Blood Spot (DBS) is considered to all infants whose mothers were found positive either during pregnancy or during labour and delivery. The DBS samples are sent to Kisumu for PCR-DNA analysis since the facility lacks the 
equipment. The DBS specimen takes approximately 2 weeks to 2 months for results to be implemented. The HIV exposed infant is then followed up in the clinic until 18 months after which it is discharged to patient support care for further management.

\subsection{Study Population}

A total of 96 HIV exposed infants were recruited during the study period. The study population included all HIV positive mothers on PMTCT programme with infants between 6 weeks and 18 months old who have been tested for HIV. The inclusion criteria were all HIV exposed infants registered in the PMTCT clinic after labour and delivery. The HIV exposed infants were brought to the PMTCT clinic and immunization services by their mothers. The exclusion criteria were all mothers with their infants below 18 months old who were not in the PMTCT program coming for postnatal clinics and immunization schedule. The HIV positive mothers who had not consented during the study period were also excluded.

The HIV exposed infants were recruited conveniently until the required sample size was attained. This was suitable because the required sample size was attained within the time frame of the study. HIV status of the infants was retrieved from HIV Exposed Infant records.

\subsection{Sample Size Determination}

The sample size determination used Fischer's et al., (1998) formula to determine the sample size as follows:

$$
n=\frac{Z^{2} P(1-P)}{d^{2}}
$$

where:

$n$ is the desired sample size (if the study population is greater than 10,000);

$Z$ is the normal standard deviation at the desired confidence level taken to be 1.96 which corresponds to $95 \%$ confidence level;

$P$ is the proportion in the target population estimated to have characteristics being measured;

$1-q$ is the proportion in the target population estimated not to have the characteristics being measured;

$d=$ Standard Error at $95 \%$ confidence limit $(0.05)$.

Since $p$ was not known, it was estimated to be 50\% (Mugenda \& Mugenda, 2003).

Therefore

$$
n=\frac{1.96^{2} \times 0.5 \times 0.5}{0.052}
$$

$n=384$ HIV mothers with infants below 18 months.

If the target population is less than 10,000, Fischer's et al. (1998) the following 
alternative formula is applied.

$$
\begin{array}{ll}
n f= & n \\
& 1+\left(\frac{n-1}{N}\right)
\end{array}
$$

where:

$n f=$ desired sample size(when the population is less than 10,000);

$n=$ sample size of population more than 10,000 (calculated as 384);

$N=$ was the estimated population within the study period which was approximately 128 (average in 3 months from the PMTCT records).

Therefore, the desired sample size was,

$$
\begin{aligned}
& n f=384 \\
& 1+\left(\frac{384-1}{128}\right)
\end{aligned}
$$

= $96 \mathrm{HIV}$ positive mothers with infants below 18 months old.

\subsection{Data Collection}

A physical visit was made to the study area, for the purpose of data collection. The data collection was done one on one interviewer administered questionnaire by 2 research assistants and the researcher. The research assistants were purposely used to avoid information bias by the researcher. The interviews were done privately and convenient place within the $\mathrm{MCH}$ clinic especially on the private and comfortable room or on the waiting bay. Each interview lasted for 10 - 25 minutes and the participants were thanked for their participation. This was done in either Kiswahili or English language.

HIV status on infants (6 weeks to 18 months) was obtained on PMTCT HIV Exposed Infant records. The participants were approached after their appointments with the health care worker and those who consented to volunteer were recruited.

\subsection{Data Quality Control Measures}

The data study tools were pre tested at Oresi health Centre which is 100 meters away from KTRH. Ten HIV mothers who met the inclusion criteria were sampled to validate the reliability of the tool before its use in the research study. Note that, the pre-tested questionnaires were not part of the sampled population.

Two research assistants were recruited and trained to avoid information bias from the researcher when interviewing the study participants during the study period. The research assistants who had background information on research methods were recruited for this purpose.

The quantitative data instruments used for data collection were handed over to the researcher at the end of each day for storage and data entry. Anonymity of the study participants and status of the infants was done through coding of re- 
search instruments. Data validation was done to correct data entry problems such as missed, double entered data values or data entered in the wrong variables.

\subsection{Data Analysis}

Quantitative data was entered and analyzed using Statistical Package for Social Sciences Version 20. Descriptive statistics was used to summarize data on infant status. Frequencies and percentages were computed and presented in frequency tables, and bar charts to emphasize on general findings and bar graphs on categorical variables such as gender, level of education, marital status, access to the health facility and occupation status and HIV status of the infant. Pearson Chi square $\left(\chi^{2}\right)$ was used to address potential differences between the status of the infants in terms of the informants' characteristics that is the socio demographic characteristics, factors associated in contributing to new HIV infection which included the ANC clinics, infant feeding options, rate of disclosure, to which the disclosure was made and place of delivery. The dependent variable, the status of the infant either HIV positive or HIV negative was used. The p-value was set at 0.05 ( $\mathrm{p}$-value $<0.05$ ).

\subsection{Ethical Consideration}

Permission to carry out the study was obtained from the Ethics Research Committee at Kenyatta National Hospital/University of Nairobi. Permission to proceed on was also sought from KTRH hospital research office management and a verbal consent was obtained from the Nursing officer in charge of $\mathrm{MCH}$ clinic.

Informed consent was obtained from the study participants who met the inclusion criteria and consent form signed before interviews commenced. The participants were interviewed in a confided room within the clinic and all the information obtained was treated with confidentiality and coding was used to protect the respondents' identity.

The data collected was kept in a locked cabinet by the researcher during the entire study period. The electronic data was secured with a password known to the researcher. There was no risk involved during the study. The benefits from the study, is that the participants who were not sure of their infants' status were informed and were also counselled on the importance of the PMTCT program. If the participants had any other issues, they were referred appropriately during the study period. The findings were communicated to the referral facility to improve the quality of care on the HIV exposed infants in the setting.

\subsection{Study Limitations}

The study was facility-based using HIV positive mothers with exposed infants below 18 months old presenting at the PMTCT follow up clinic from 6 weeks. Only those who met the inclusion criteria and consented to participate were 
recruited during the study period. This could be attributed to be either a possible under estimation or over estimation on infant HIV infection prevalence rate.

Only those who were willing to participate were included. This could have introduced selection bias since it is difficult to know whether or not the responses given are representative of the whole eligible population. This means that the extent to which the results can be generalized is limited.

Data collected was based on interviews and relied on the memory of informant (mothers). This showed recall bias on reason for admission and disclosure issues.

\section{Results and Discussion}

A total of 96 infants below 18 months of age with HIV mothers on PMTCT programs at Kisii Teaching and referral hospital $\mathrm{MCH}$ clinic were recruited during the study period. The sampled population of infants gave a response rate of $100 \%$ and this was because their mothers were positive of their health well being on the PMTCT program.

\subsection{Socio-Demographic Characteristics}

The highest proportion of mothers (40.6\%) was in age group 28 - 32 years. The mean and median maternal age was 29.69 and 30 years. The study revealed that most $(68.8 \%)$ of the respondents were married followed by singles at $15.6 \%$. More than half (54.2\%) attained secondary school education. On their monthly income status, most (35.43\%) were earning between Kshs. 3001 - 5000 with more than half (54.2\%) being self-employed. On being asked how they access the facility, half (50\%) of the respondents stated on the use of public service vehicle (Table 1).

\subsection{Prevalence of New HIV Infection among HIV Exposed Infants}

A total of 96 HIV positive mothers of reproductive age (18 - 45 years) with infants aged 3 - 18 months participated in the study. Out of the sampled population, $13.5 \%$ (95\% CI $=10.1 \%$ to $16.9 \%$ ) of the infants below 18 months were found to be HIV positive despite their mothers being on the PMTCT program shown in Figure 1.

From this study, it was found that the prevalence of infants born of HIV positive mothers was $13.5 \%$ compared to national current prevalence of mother to child transmission at 14\% [11]. Comparable to study done by NASCOP (2012) on Kenya Aids Indicator Survey, on the $90 \%$ of the mothers or infants who utilized PMTCT intervention $16 \%$ were HIV positive at six weeks [1]. In the study, the new HIV infections among infants were found after delivery and most were found infected by 9 months as compared at 6 weeks. Whilst those who indicated they have been tested thrice were all found to be negative. 
Table 1. Socio demographic characteristics of the Respondents.

\begin{tabular}{|c|c|c|}
\hline Background information & Frequency $(n=96)$ & Percentage (\%) \\
\hline \multicolumn{3}{|l|}{ Age in years (mothers) } \\
\hline $18-22$ & 10 & 10.4 \\
\hline $23-27$ & 28 & 29.2 \\
\hline $28-32$ & 39 & 40.6 \\
\hline $33-37$ & 13 & 13.5 \\
\hline $38-42$ & 5 & 5.2 \\
\hline $43-47$ & 1 & 1.0 \\
\hline \multicolumn{3}{|l|}{ Marital status } \\
\hline Single & 15 & 15.6 \\
\hline Widow & 13 & 13.5 \\
\hline Married & 66 & 68.8 \\
\hline Divorced/separated & 1 & 1.0 \\
\hline cohabiting & 1 & 1.0 \\
\hline \multicolumn{3}{|l|}{ Level of education } \\
\hline None & 1 & 1.0 \\
\hline Primary & 31 & 32.3 \\
\hline Secondary & 52 & 54.2 \\
\hline $\begin{array}{c}\text { Tertiary } \\
\text { Occupation }\end{array}$ & 12 & 12.5 \\
\hline Housewife & 24 & 25.0 \\
\hline Self employed & 43 & 44.8 \\
\hline Formal employment & 14 & 14.6 \\
\hline Informal/casual employment & 12 & 12.5 \\
\hline Farming & 1 & 1.0 \\
\hline None & 2 & 2.1 \\
\hline \multicolumn{3}{|l|}{ Income per month } \\
\hline $500-3000$ & 22 & 22.9 \\
\hline $3001-5500$ & 34 & 35.4 \\
\hline $5501-8000$ & 12 & 12.5 \\
\hline $8001-10,500$ & 6 & 6.2 \\
\hline $10,501-13,000$ & 4 & 4.2 \\
\hline $13,001-15,500$ & 5 & 5.2 \\
\hline $15,501-18,000$ & 0 & 0.0 \\
\hline $18,001-21,500$ & 2 & 2.1 \\
\hline$>21,500$ & 7 & 7.3 \\
\hline No Income & 4 & 4.2 \\
\hline \multicolumn{3}{|l|}{ Transport to facility } \\
\hline Walking & 20 & 20.8 \\
\hline Bodaboda/bicycle & 25 & 26.0 \\
\hline Public service vehicle & 48 & 50.0 \\
\hline Private & 3 & 3.1 \\
\hline \multicolumn{3}{|l|}{ Who do you live with } \\
\hline your partner & 67 & 69.8 \\
\hline family/relatives & 24 & 25.0 \\
\hline friend & 3 & 3.1 \\
\hline none & 2 & 2.1 \\
\hline
\end{tabular}




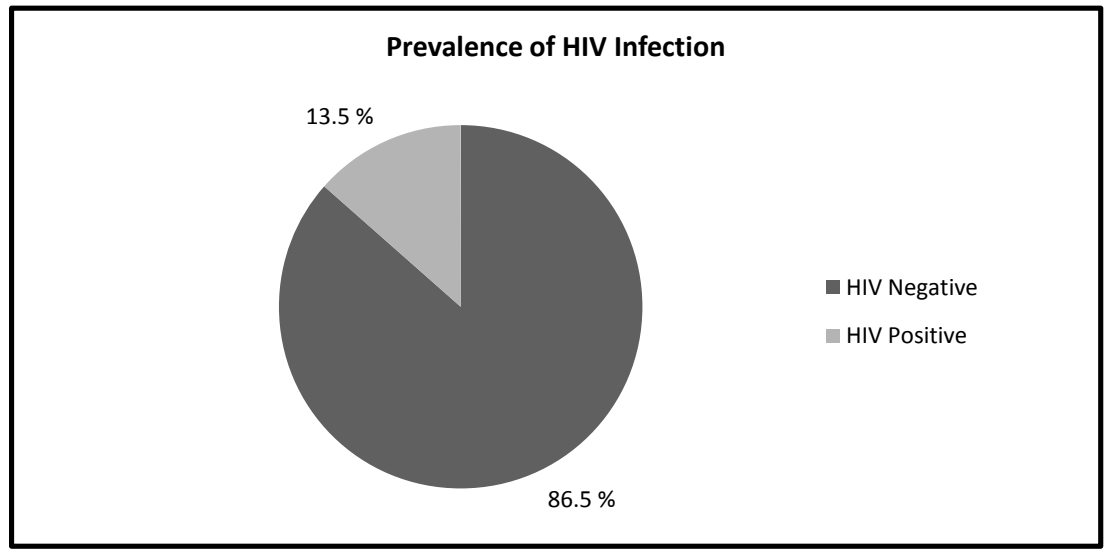

Figure 1. Prevalence of HIV Infection.

These findings show that the HIV infections may be due to maternal antibodies of the mother in health law of testing infants that HIV transmission in infants is approximately $9 \%$ at day 3 of life and rises to approximately $18 \%$ later in life. The testing of infants early in life show that they are exposed to maternal antibodies until they produce their own antibodies at around 18 months of age [12].

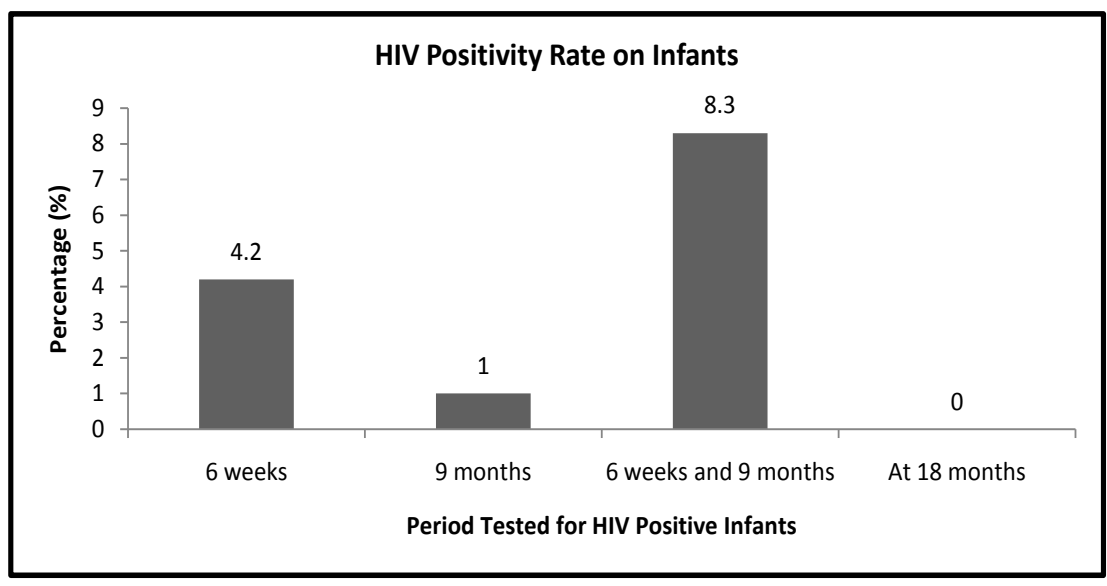

Findings from the study showed that, out of those infants who were tested and found out to be infected by their mothers, majority (8.3\%) became HIV positive after a repeat test was done giving a difference of $4.1 \%$. This indicates that HIV infection doubled during breast feeding of infants. While those who were tested 3 times turned negative and this could be attributed to effectiveness of the PMTCT program in follow up of mothers with infants until completion of the program. This was found to be consistent with other studies and reviews on the PMTCT program [13] [14] [15].

\subsection{Factors Associated with New HIV Infections among HIV Exposed Infants}

From Table 2, all contributing factors were cross tabulated and Pearson chi 
square used with the HIV status of the Infant. Those that were found to be statistically significantly $(\mathrm{p}$-value $=0.001)$ were place of delivery $\left(\chi^{2}=29.289, \mathrm{df}=\right.$ 2 , -value $=0.001)$, infant prophylaxis at birth $25.586, \mathrm{df}=1, \mathrm{p}$-value $=0.001)$, follow up medication of the infant $\left(\chi^{2}=20.496, \mathrm{df}=2\right.$, p-value $\left.=0.001\right)$ and infant feeding methods $\left(\chi^{2}=48.149, \mathrm{df}=3, \mathrm{p}\right.$-value $\left.=0.001\right)$. The infant feeding options was a risk factor in MTCT of HIV whereas place of delivery, ARV prophylaxis and follow up medication were found to be protective in MTCT of HIV.

Table 2. Bivariate Analysis of Factors Associated to HIV Status of Infants.

\begin{tabular}{|c|c|c|c|c|c|c|}
\hline \multirow[t]{2}{*}{ Contributing Factors } & \multicolumn{3}{|c|}{ HIV status } & \multirow{2}{*}{$\chi^{2}$} & \multirow{2}{*}{ df } & \multirow{2}{*}{$\mathrm{p}$ value } \\
\hline & \multicolumn{3}{|c|}{ Negative n (\%) Positive n (\%) } & & & \\
\hline \multicolumn{7}{|c|}{ Starting of Antenatal Visits } \\
\hline $0-3$ months & $43(51.8 \%)$ & $3(23.1 \%)$ & $46(47.9 \%)$ & & & \\
\hline $4-6$ months & $28(33.7 \%)$ & $8(61.5 \%)$ & $36(37.5 \%)$ & & & \\
\hline 7 - 9 months & $8(9.6 \%)$ & $1(7.7 \%)$ & $9(9.4 \%)$ & 4.477 & 3 & 0.214 \\
\hline Didn't attend clinics & $4(4.8 \%)$ & $1(7.7 \%)$ & $5(5.2 \%)$ & & & \\
\hline \multicolumn{7}{|c|}{ HIV Testing with Current Infant } \\
\hline $\begin{array}{l}\text { During pregnancy } \\
\text { (ANC visits) }\end{array}$ & $48(57.8 \%)$ & $4(30.8 \%)$ & $52(54.2 \%)$ & & & \\
\hline During labour & $8(9.6 \%)$ & $1(7.7 \%)$ & $9(9.4 \%)$ & & & \\
\hline After delivery & $7(8.4 \%)$ & $3(23.1 \%)$ & $10(10.4 \%)$ & & & \\
\hline $\begin{array}{c}\text { Voluntary counselling } \\
\text { and testing }\end{array}$ & $19(22.9 \%)$ & $4(30.8 \%)$ & $23(24.0 \%)$ & 10.711 & 5 & 0.057 \\
\hline Home visit & $1(1.2 \%)$ & $0(0.0 \%)$ & $1(1.00 \%)$ & & & \\
\hline In the ward & $0(0.0 \%)$ & $1(7.7 \%)$ & $1(1.0 \%)$ & & & \\
\hline \multicolumn{7}{|c|}{ Maternal PMTCT Intervention } \\
\hline Already in ART & $37(44.6 \%)$ & $3(23.1 \%)$ & $40(41.7 \%)$ & & & \\
\hline Single dose Nevirapine & $4(4.8 \%)$ & $0(0 \%)$ & $4(4.2 \%)$ & & & \\
\hline Single dose Nevirapine + AZT & $3(3.6 \%)$ & $2(15.6 \%)$ & $5(5.2 \%)$ & 6.142 & 4 & 0.189 \\
\hline $\mathrm{SD} \mathrm{NVP}+3 \mathrm{TC}+\mathrm{AZT}$ & $3(3.6 \%)$ & $0(0 \%)$ & $3(3.1 \%)$ & & & \\
\hline Septrin + Multivitamin & $36(43.4 \%)$ & $8(61.5 \%)$ & $44(45.8 \%)$ & & & \\
\hline \multicolumn{7}{|c|}{ Place of Delivery } \\
\hline At home & $4(4.8 \%)$ & $5(38.5 \%)$ & $9(9.4 \%)$ & & & \\
\hline Health facility & $79(95.2 \%)$ & $6(46.2 \%)$ & $85(88.5 \%)$ & 29.389 & 2 & 0.001 \\
\hline On the way to hospital & $0(0 \%)$ & $2(12.5 \%)$ & $2(2.1 \%)$ & & & \\
\hline \multicolumn{7}{|c|}{ ARV Prophylaxis at Birth } \\
\hline Received ARV Prophylaxis & $78(94.0 \%)$ & $5(38.5 \%)$ & $83(86.5 \%)$ & & & \\
\hline $\begin{array}{c}\text { Did not receive ARV } \\
\text { prophylaxis }\end{array}$ & $5(6.0 \%)$ & $8(61.5 \%)$ & $13(13.5 \%)$ & 29.586 & 1 & 0.0001 \\
\hline
\end{tabular}




\section{Continued}

\begin{tabular}{|c|c|c|c|c|c|c|}
\hline \multicolumn{7}{|c|}{ Follow Up Medication of Infant } \\
\hline Sd NVP & $80(96.4 \%)$ & $9(69.2 \%)$ & $89(92.7 \%)$ & \multirow{3}{*}{20.496} & \multirow{3}{*}{2} & \multirow{3}{*}{0.0001} \\
\hline $3 \mathrm{TC}+\mathrm{AZT}+$ Kaletra & $3(3.6 \%)$ & $1(7.7 \%)$ & $4(4.2 \%)$ & & & \\
\hline Septrin and Multivitamin & $0(0.0 \%$ & $3(23.1 \%)$ & $3(3.1 \%)$ & & & \\
\hline \multicolumn{7}{|c|}{ Admission of Infant } \\
\hline Admitted & $18(21.7 \%)$ & $4(30.8 \%)$ & $22(22.9 \%$ & \multirow{2}{*}{0.525} & \multirow{2}{*}{1} & \multirow{2}{*}{0.469} \\
\hline Not admitted & $65(78.3 \%)$ & $9(69.2 \%)$ & $74(77.1 \%)$ & & & \\
\hline \multicolumn{7}{|c|}{ Infant Feeding Methods } \\
\hline Mixed feeding & $4(4.8 \%)$ & $10(76.9 \%)$ & $14(14.6 \%)$ & \multirow{4}{*}{48.149} & \multirow{4}{*}{3} & \multirow{4}{*}{0.0001} \\
\hline Replacement feeding & $4(4.8 \%)$ & $1(7.7 \%)$ & $5(5.2 \%)$ & & & \\
\hline Breastfeeding for 6 months 7 & $71(85.5 \%)$ & $2(15.4 \%)$ & $73(76.0 \%)$ & & & \\
\hline Exclusive formula feeding & $4(4.8 \%)$ & $0(0.0 \%)$ & $4(4.2 \%)$ & & & \\
\hline \multicolumn{7}{|c|}{ Disclosure of HIV Status } \\
\hline Yes & $60(72.3 \%)$ & $6(46.2 \%)$ & $66(68.8 \%)$ & \multirow{5}{*}{4.712} & \multirow{5}{*}{4} & \multirow{5}{*}{0.318} \\
\hline No & $4(4.8 \%)$ & $1(7.7 \%)$ & $5(5.2 \%)$ & & & \\
\hline No because of stigma issues & $10(12.0 \%)$ & $2(15.4 \%)$ & $12(12.5 \%)$ & & & \\
\hline No because of fear & $7(8.4 \%)$ & $3(23.1 \%)$ & $10(10.4 \%)$ & & & \\
\hline No because I live alone & $2(2.4 \%)$ & $1(7.7 \%)$ & $3(3.1 \%)$ & & & \\
\hline \multicolumn{7}{|c|}{ To Whom Disclosure Status Was Made } \\
\hline Partner & $52(62.7 \%)$ & $6(46.2 \%)$ & $58(60.4 \%)$ & \multirow{4}{*}{4.216} & \multirow{4}{*}{3} & \multirow{4}{*}{0.239} \\
\hline Friend/Relative & $7(8.4 \%)$ & $0(0.0 \%)$ & $7(7.3 \%)$ & & & \\
\hline $\begin{array}{c}\text { Family member } \\
\text { (parent, brother, sister) }\end{array}$ & $1(1.2 \%)$ & $0(0.0 \%)$ & $1(1.0 \%)$ & & & \\
\hline None & $23(27.7 \%)$ & $7(53.8 \%)$ & $30(31.3 \%)$ & & & \\
\hline
\end{tabular}

Generally, from the study, the factors that were associated with reduction of new HIV infections had an association which were statistically significant ( $\mathrm{p}<$ 0.001). These were place of delivery, infant prophylaxis at birth, and follow up medication of the infant.

The findings in this setting indicated that those who delivered at the hospital reduced the risk of HIV infection among infants born of HIV positive mothers although caesarian mode of delivery did not achieve statistical significance because of the small sample size. This study is consistent with the findings [3] that those who delivered in hospital reduced MTCT of HIV. In cross tabulation with level of education and delivery place it was statistically significant that those with high education chose health facility delivery. This was consistent with study findings in Kitale that those who did not deliver in a health facility were less educated [9].

Anti-retroviral treatment in Kisii Teaching and Referral hospital is partnered with NASCOP and CARE Kenya who support PMTCT program in training staff, 
providing drugs and testing kits for free on PMTCT program. This has enabled the delivery of the PMTCT services in the facility. Use of antiretroviral drugs from other studies and systematic reviews has shown to reduce the risk of mother to child transmission by lowering plasma viral load in pregnant women or when given as post-exposure prophylaxis in the newborns [1] [2] [3] [16]. It was evident from the study that use of ARV prophylaxis at birth, single dose $\mathrm{Ne}$ virapine and follow up treatment to infants reduced the risk of transmission.

A systemic study review done [9] [14] indicates that some participants who missed treatment gave the reasons which were consistent with findings in this study where a proportion of mothers and infants indicated that they missed treatment due to travelling out of town, drugs being out of stock, forgotten and work related issues. Missed treatment was attributed to travelling out of town whilst lack of transport was attributed to socio economic status of the participants in accessing the facility due to poverty issues.

Infant feeding is a major influence in the child survival in the context of HIV. Findings indicated that those who were HIV infected were mostly due to mixed feeding and this was significantly associated with HIV status of the infant $\left(\chi^{2}=\right.$ $48.149, \mathrm{p}<0.001$ ) whilst breastfeeding for 6 months was found to be protective, the findings were similar to Ngwede et al. [3]. The use of exclusive formula milk was also found to be very effective with the PMTCT goal to zero elimination of new infections by 2015 .

The rate of disclosure was high in a relationship especially partners, this findings were similar to a study done by Ngigi et al. [17].

\section{Conclusion and Recommendation}

The study has confirmed that there is still new HIV infections among infants especially in low resource limited setting and the main reason for these new HIV infections is through mixed feeding.

In general the PMTCT service utilization was found to be effective in high level of early infant diagnosis and a high level of awareness of MTCT/PMTCT in the part of the women.

This study shows that there are factors which are significantly associated with new HIV infections among HIV exposed infants on PMTCT program at Kisii Teaching and Referral Hospital. Mixed feeding was found to be the risk factor in the transmission of HIV infections.

On the other hand, factors that were significantly associated with reduction of HIV infections from mother to child transmission were use of antiretroviral treatment in children and this included use of Nevirapine at birth, anti-retroviral treatment of the infant and hospital delivery. Support from donors was found to be beneficial on the PMTCT program in training staff and availability of resources.

With an observation made in the study there was virtual elimination of HIV infections on all the respondents who used exclusive formula feeding and use of highly anti-retroviral therapy though this being a low resource setting. 
The findings of this study provide valuable information for improving the quality of programs to prevent mother to child transmission of HIV in the study setting and other areas.

\section{Recommendation}

Based on the findings, following recommendations were made;

- Health care workers as the main source of information should be exposed for regular training programme by the hospital to update their skills and knowledge on PMTCT update to provide quality care to their clients/patients.

- Being a low resource setting, health care workers must encourage exclusive breast feeding period for 6 months and stop breast feeding if acceptable, feasible, affordable, sustainable and safe since early cessation of breastfeeding leads to transmission of new HIV infection in infants.

- HIV exposed mothers should be invited during peer support group to encourage mothers fellow mothers to embrace exclusive breast milk for 6 months since is was found to be protective.

- Self-stigmatization and discrimination is a challenge on disclosure issues, choice of infant feeding methods and adherence to treatment therefore health care workers should sensitize couple counseling of the HIV positive mothers, on infant feeding methods and treatment adherence.

- Health care workers at the maternal and child health to empower mothers on use of exclusive formula feeding and provide anti-retroviral therapy to all infants in the virtual elimination of the new HIV infections.

The findings of this study provide valuable information for improving the quality of programs to prevent mother to child transmission of HIV in the study setting, while further studies need to follow up the challenges within the program.

\section{Acknowledgements}

We thank the administration of Kisii Teaching and referral hospital for the permission to carry out the study. All authors read and approved the final manuscript. Moi Teaching and Referral Hospital for allowing me to do my studies in Community health nursing.

\section{Author's Contribution}

M.N.A. conceptualize on the study, designing the study, data collection, analysis and report writing and drafting the manuscript G.M.O and T.M.O. participated in the revision of the intellectual content of the research article P. O. A. participated in the conceptualization and intellectual content of the study. All authors read and approved the final manuscript.

\section{Financial Disclosure}

No financial disclosures were reported by the authors of this paper. 


\section{Conflicts of Interest}

The authors declare no competing interest.

\section{References}

[1] Ministry of Health (2013) National AIDS and STI Control Programme. Kenya AIDS Indicator Survey 2012: Preliminary Report. Nairobi, in press.

[2] Centre for Disease and Control and Prevention (2014) Eliminating HIV Infections in Children and Keeping Their Mothers Alive. In press.

[3] Ngwede, S., Gombel, N. and Midzi, S. (2008) Factors Associated with HIV Infection among Children Born to Mothers on the Prevention of Mother to Child Transmission Programme at Chitungwiza Hospital, Zimbabwe. BMC Public Health, in press.

[4] Mahy, M., Stover, J., Kiragu, K. and Hayashi, C. (2010) What Will It Take to Achieve Virtual Elimination of Mother to Child Transmission of HIV? An Assessment of Current Progress and Future Needs. Journal of Sexually Transmission Infection, 86, ii48-ii55.

[5] Sidibé, M. (2013) Joint United Programme on HIV/AIDs (UNAIDS). Global Report UNAIDS Report on the Global AIDs Epidemic. In press.

[6] UNICEF (2013) Towards an AIDS-Free Generation-Children and AIDS: Sixth Stocktaking Report. United Nations Children's Fund, New York, 38-42, in press.

[7] Mbori-Ngacha, D. and Schaffer, N. (2010) Prevention of Mother to Child Transmission and Peadriatric HIV/AIDS Care and Treatment. Joint IATT Technical Review Mission Report, Ministry of Public Health and Sanitation, Government of Kenya, in press.

[8] Dutta, A., Kripke, K., Mwai, D. and Sirengo, M. (2013) Prevention of Mother to Child Transmission in Kenya: Cost Effectiveness of Option B+. In press.

[9] Kinuthia, J., Kiarie, J., Farquhar, C., et al., (2011) Uptake of Prevention of Mother to Child Transmission Interventions in Kenya: Health Systems Are Most Influential than Stigma. Journal of International Aids society, 14, 61. https://doi.org/10.1186/1758-2652-14-61

[10] Ciaranello, A.L., Perez, F. and Keatinge, J. (2012) What Will It Take to Eliminate Pediatric HIV? Reaching WHO Target Rates of Mother-to-Child HIV Transmission in Zimbabwe: A Model-Based Analysis. PLoS Medicine, 9, e1001156. https://doi.org/10.1371/journal.pmed.1001156

[11] Ministry of Health (2014) National AIDS and STI Control Programme (NASCOP), Kenya HIV Prevention Revolution Road Map, Count Down 2030. Nairobi.

[12] Schleiter, K.E. (2009) Testing Newborns for HIV. American Medical Association Journal of Medical Ethics, 11, 969-973.

[13] Tudor Car, L., Brusamento, S., Elmoniry, H., van Velthoven, M.H.M.M.T., Pape, U.J., Welch, V., Tugwell, P., Majeed, A., Rudan, I., Car, J. and Atun, R. (2013) The Uptake of Integrated Perinatal Prevention of Mother-to-Child HIV Transmission Programs in Low- and Middle-Income Countries: A Systematic Review. PLoS ONE, 8, e56550. https://doi.org/10.1371/journal.pone.0056550

[14] Gourlay, A., Birdthistle, I., Mburu, G., Iorpenda, K. and Wringe, A. (2013). Barriers and Facilitating Factors to the Uptake of Antiretroviral Drugs for Prevention of Mother-to-Child Transmission of HIV in Sub-Saharan Africa: A Systematic Review. Journal of the International AIDS Society, 16, Article ID: 18588. https://doi.org/10.7448/IAS.16.1.18588 
[15] Ndubuka, J., Ndubuka, N., Li, Y., Marshall, C.M. and Ehiri, J. (2013) Knowledge, Attitude, and Practice regarding Infant Feeding among HIV Positive Pregnant Women in Gaborone, Botswana: A Cross Sectional Survey. BMJ Open, 3, e003749.

[16] Siegfried, N., van der Merwe, L., Brocklehurst, P. and Sint, T.T. (2011) Antiretrovirals for Reducing the Risk of Mother-to-Child Transmission of HIV Infection. Cochrane Database of Systematic Reviews, No. 7, CD003510.

[17] Ngigi, P.W., Othero, M.D. and Odero, O.W. (2011) Prevalence of Serostatus Disclosure to Sexual Partners among HIV Infected Women in Kisii District, Western Kenya. East Africa Medical Journal, 88, 80-85. 


\title{
List of Abbreviations
}

\author{
ANC-Antenatal Clinic \\ ARV - Anti Retroviral Drug \\ DNA-Deoxyribonucleic Acid \\ DBS-Dried Blood Spot \\ EID_Early Infant Diagnosis \\ Kshs.-Kenya Shillings \\ KTRH-Kisii Teaching and Referral Hospital \\ MTCT-Mother to Child Transmission \\ MCH-Maternal and Child Health \\ PMTCT-Prevention of Mother to Child Transmission \\ PCR-Polymerase Chain Reaction \\ WHO-World Health Organization
}

\section{Appendix I: Questionnaire for Mothers with Infants}

\section{FACTORS ASSOCIATED WITH NEW HIV INFECTIONS AMONG INFANTS BORN OF HIV POSITIVE MOTHERS AT KISII TEACHING AND REFERRAL HOSPITAL, KENYA}

Serial No:

Date of interview:

Introduction

The purpose of this study is get information about you and your infant to assess the status of new HIV infection despite being in the PMTCT programme. All questions will be asked to provide information. The status of your infant will be assessed using the mother booklet or PMTCT health registers. The information is confidential and will be used for data analysis purposes.

\section{SECTION I: Background Information}

1) How old are you in years?

2) Marital status.
$\square$ Single
Widow
Married
$\square$ Divorced/separate
$\square$ Cohabiting
$\square$ Others' specify

3) Level of education.
$\square$ None
$\square$ Primary Secondary
$\square$ Tertiary
$\square$ Others' specify

4) Occupation.
$\square$ House wife
Self-employed
Formal employment

$\square$ Informal/casual employment

Others' specify

5) How much is your estimated income per month? ..... Kenya shillings

6) How do you come to this facility?
$\square$ Walking
Bodaboda/Bicycle
$\square$ Public Service Vehicle
$\square$ Private

7) Who do you live with.
$\square$ Your partner
Family/Relatives/Friend
None 


\section{SECTION II: Factors Contributing to New Infections}

8) When did you start your antenatal visits with your current infant?
$\square 0$ - 3 months
$\square$ - 6 months
7 - 9 months

$\square$ Did not attend any clinics

9) When did you learn of your current HIV status?
$\square$ During pregnancy (ANC visits)
During labour
$\square$ After delivery $\square$ Voluntary counseling and testing
$\square$ Other(s) specify

10) What maternal PMTCT intervention are you using?
$\square$ Already on ART
$\square$ Single dose Nevirapine
$\square$ Single dose Nevirapine + AZT
$\square$ Single dose + AZT
Single dose $+3 \mathrm{TC}+\mathrm{AZT}$
$\square$ Cotrimoxazole + Multivitamin

11) Have you ever missed treatment?
$\square$ Yes
$\square$ No

a) If yes to the above, how many times?

b) What are the reasons for missing the treatment?

12) Where was your delivery with the infant?

$\square$ At home/At health facility $\square$ On the way to hospital
a) If at the health facility, which mode of delivery?
$\square$ Caesarean section $\square$ No Caesarian section

13)Did your infant receive ARV prophylaxis at birth? $\square$ Yes $\square$ No

14)On follow up, what treatment did your infant use?

$\square$ None $\square$ Single dose Nevirapine $\square$ Single dose Nevirapine + AZT

$\square$ Single dose Nevirapine + AZT $\square$ Other(s) specify

15)Has your infant ever missed treatment? $\square$ Yes $\square$ No

a) If yes to the above, how many times?

b) What are the reasons for missing of the treatment?

16)a) Has your infant ever been admitted before? $\square$ Yes $\square$ No

b) What was/were the reason for admission

17)a) What feeding options did you use for your infant?

$\square$ Mixed breast feeding $\square$ Replacement feeding

$\square$ Exclusive breast feeding for 6 months $\square$ Exclusive formula feeding

b) What made you choose these feeding options (above)?

$\square$ Stigma (to avoid) $\square$ Affordable

Effectiveness $\square$ Others specify

18)Have you ever missed your clinic appointments? $\square$ Yes $\square$ No

a) If yes, why.

19)Did you disclose your positive HIV status?

$\square$ Yes $\square$ No $\square$ No to avoid stigma issues

$\square$ No because of fear $\square$ No because 1 live alone

Other(s) specify

a) If Yes above, to whom did you disclose your positive HIV status?
$\square$ Your partner
$\square$ Family member (brother, sister, parent)
$\square$ Friend/Relative None 


\section{Section III: HIV Status of the Infant}

20) Age (in months) of your infant

21)Gender of your infant $\square$ Male $\square$ Female

22)Has your infant been tested for HIV? $\square$ Yes $\square$ No

23)What was the HIV status of your baby? $\square$ Negative

$\square$ Positive

24)When was the baby tested for HIV

$\square$ At 6 weeks $\square$ At 9 months

$\square$ At 6 and 9 months $\square$ At 18 months

Thank you for your participation 